« Learning to Read in the Digital Age : From Reading Texts to Hacking Codes »,

PMLA, 130.3 (2015), p. 743-749.

Yves Citton

\title{
Learning to Read in the Digital Age: from Reading Texts to Hacking Codes
}

Reading is still often perceived as the decoding of a message, as if the message were meant to be merely "received", as if the code were supposed to be known and invariable, and as if the meaning were determined solely by the sender. Since the 1960s at least, however, theories of interpretation have constructed (literary) reading in a more elaborate and inventive fashion: while each author was supposed to re-invent a singular language against the background of the common language, each interpreter necessarily had to re-create something new, even though reading exactly the same text, because each interpreter understood this text and its singular language within an ever-changing context of actualization. The model of interpretation, however, remained indebted to the activity of deciphering: the ever-changing meaning was to be found within the text itself.

Both the CCSI initiative and, in Europe, the guidelines periodically imposed upon teachers by ministries of Education register this evolution from decoding to interpretation. Whether in the form of ambitious (although often hollow) preliminary declarations about "critical-thinking", or in the form of more precise assessment criteria, most of these administrative documents recognize that reading involves more than merely deciphering an unequivocal message. The CCSSI displays insight when it asks students to "determine the meaning of words and phrases as they are used in a text, including analyzing how an author uses and refines the meaning of a key term over the course of a text (e.g., how Madison defines faction in Federalist No. 10)" (CCSSI Standards 40). In such statements, literacy is clearly defined in terms of interpretation rather than reading: the student cannot simply apply a proper knowledge of "the" English language on a text in order to extract its proper meaning; s/he must (re)construct a singular version of the language drafted by this singular author in order to make sense of its potential signification.

The presence of such formulations in these types of regulatory documents should be celebrated by literary scholars, since they imply that there can be no real literacy that is not literary. The quasi-obsessive insistence of the CCSS on "cit[ing] strong and thorough textual evidence to support analysis of what the text says" (CCSSI Standards 36, 38, 39, 40) should also be welcome, given the significance of close reading for literary studies. As we enter the digital age, however, a new "post-interpretive" configuration seems to emerge, not to replace but rather to supplement our traditional conceptions of reading and interpretation. As Lev Manovich, Lawrence Lessig and many others have shown, variability, modularity, hybridization, recombination, remix are crucial properties of "new media". Their main consequence is to explode the very notion of "the text". Through the extensive use of the "copy", "search", "cutand-paste" functions, through the practices of sampling, inserting, transferring, syndicating, reediting, it is not only the integrity and the borders of "the text" that are altered and need to be reassessed: it is the reader's relation to the readable data that is mutating. "Data" (texts, slogans, keywords, tags, tweets, images, icons, logos, sounds, videos) are given only to be re-processed: to read is no longer only to decipher, nor merely to re-construct or de-construct, but also to re-use, 
re-shape and over-code. The re-contextualization which, in the age of interpretation, altered the meaning of the text (its "content"), now reconfigures its signs themselves (its "form").In this digital context, it is significant to see literary scholars describe literary interpretation by emphasizing the notion of "use" (Rita Felski), by adding "distant reading" (Franco Moretti), "hyper-reading" (N. Katherine Hayles) to the traditional practice of close reading, or by valorizing (rather than stigmatizing) the practice of "continuous partial attention" as "a digital survival skill", against the dogma of attentiveness equated with focalization (Cathy Davidson). In the digital age, learning to read means learning to properly and inventively use the (overwhelming) context of whatever is accessible through search engines, i.e., of whatever resonates through the dense and unpredictable web of hyperlinks.

This new mode of reading calls for new modes of teaching. As David M. Berry has suggested, we are entering a third wave of digital humanities, where the greatest challenge consists in collectively constructing sustainable and desirable "computational subjectivities". Just like this third wave elaborates on the two previous ones (rather than replaces them), similarly, the new demands of digital literacy supplement the previous demands of deciphering and interpretation inherited from the $20^{\text {th }}$ century.

Far from denouncing the emphasis put by the CCSSI on close attention to textual evidence "as a conservative return to New Criticism"1, literary scholars could welcome it as promoting a form of intellectual discipline - emanating from, and nurturing, a most valuable sensitivity to the "the letter" of the text-which needs to be strongly supported throughout our various semiotic experiences. Because so many stimuli constantly demand our attention, the capacity to concentrate and focus our minds on strings of characters, humbly to submit our understanding to the inherent logic of their syntax and semantics, remains more important than ever. The practice of close reading (as a mode of deciphering) rightly deserves to remain at the core of literary studies - against certain tendencies, prevalent with the dominance of Cultural Studies, to pay more attention to ideologies, imaginaries and stereotypes than to the signs themselves. This implies that texts have to be somewhat closed on themselves-artificially but nevertheless necessarily. From K through 12, reading texts (or film sequences, or pictures, or sounds) provides a basic lesson in humility: the semiotic data are a primary form of "otherness"; the reader must begin by opening herself to their alterity.

Of course, nobody can approach semiotic data without bringing along her personality and her culture, as well as idiosyncratic fantasies or else, common stereotypes often built into language itself. Even in the artificial context of a classroom, each reader looks at the same text from a slightly different perspective, constructing meanings with relative freedom and creative invention (Citton 2007 and 2010; Felski). If the text is necessarily closed upon itself by the very act of reading, interpretive activity is generally less geared towards bringing it back to its original truth, but more often towards sharpening its possible uses for present purposes. The activity of reading deciphers (past) signs only to invent (ever-self-renewing) meanings. While signs are data, meanings are always-to-be-updated.

There is another activity intensely engaged in reading texts and updating meanings that is less well accounted for by the CCSI and similar administrative documents currently produced around the world. By overlooking or willfully neglecting this other aspect of reading, we are missing important opportunities to "plug" our literary traditions into the current craze for "new media" and digital humanities. This silence tells us, meanwhile, about the biases (social, political,

\footnotetext{
${ }^{1}$ As reported by Margaret W. Ferguson, who was not expressing her personal view in this quote, but providing a panorama of the various contradictory reactions generated by the CCSSI among college teachers.
} 
and anthropological) that permeate the discursive genre of pedagogical guidelines and administrative standards - and it invites a consideration of another reading practice.

If indeed reading a literary text consists, as Barthes taught us half a century ago, in learning a "new language" elaborated by its author as a singular appropriation of our common language, the particular skills developed by literary studies are ALSO intimately linked to the practice of hacking the code. The activity of "hacking" is to be understood here less in its cybercriminal meaning of infiltrating a system with malevolent intent, than in the broader sense devised by Ken McKenzie Wark in his Hacker Manifesto. WARK opposes a "hacker class", made up of all the people who produce the content that feeds the Internet, to a "vectorialist class", who owns the means of accessing and valorizing this content. New forms of class struggles must therefore be identified between content-providers and access-providers-with the much-discussed issues of intellectual property, open-source software, free labor, gamification and "playbor" being the new hot political topics of the day (see Terranova, Pasquinelli, Scholtz and Multitudes).

One can describe "hacking" as a form of reading which does not accept codes as they come merely to use, verify and reproduce them, but which - in the tradition of Roland Barthes's definition of literature-never simply "receives" a message without questioning, altering, twisting, updating not only the meaning one can extract out of a set of data, but also the very code which generates these meanings. And since codes are generators of signals, hackers use given data to produce altered data through over-coding their generative protocols. While reading texts provides an encounter with alterity, hacking the codes provides opportunities for alteration.

In this broad sense, hacking refers less to technical skills than to a form of bricolage (the type of "tinkering" involved in home-improvement): while one tends to envision programmers and software designers along the "scientific" model of the engineer, hackers tend to operate along the "savage" model of tinkering, meeting practical needs with the limited toolbox of "whatever is at hand", bending and re-appropriating uses rather than engineering products (Levi-Strauss 20; Citton 2014). More importantly, against the economic model which underscores the rhetoric and very conception of the CCSSI (as well as the other similar regulations inspired by the PISAinduced competition for more efficient education among OECD countries), hacking is geared towards the irruption of exploits rather than towards the production of commodities.

Alexander Galloway and Eugene Thacker define the exploit as a mode of action (and of activism) most adapted to the current diffusion of power through "protocols" (Galloway 2004), which operate as codes governing the syntax rather than the semantic of what is allowed to circulate within a network. Hacking corresponds to an age when "protological struggles do not center around changing existent technologies, but instead involve discovering holes in existent technologies and projecting potential change through these holes. Hackers call these holes "exploits"' (Galloway and Thacker 81). This mode of behavior is strikingly similar to what has been performed for decades (and indeed centuries) by literary interpreters, who make it a rule not to change a iota in the texts they read, but instead attempt to discover polysemic holes in their explicit message, in order to project potential changes of meaning through these holes.

As mentioned earlier, the main difference between the hacker, the reader and the interpreter is that the latter two refrain from altering in any way their object of attention (the sacralized Text), whereas the former intervenes to modify not just the meaning to be extracted, but the very form and substance of the code (protocol/vector/network) s/he hacks. This, of course, has countless consequences relative to the status of the "work": this expression refers no longer to the text, the painting, the film or the performance (the work-as-created-once-and-for-all), but to a permanent human activity of making-sense of our ever-changing world by constantly adapting it to new needs, new contexts, new struggles (a work-in-progress). 
Just like Alan Kay defined the computer as a "metamedium" (Manovich 2013 101-106), the hacker deserves to appear as a "meta-reader": an interpreter who reconditions not only the meaning, but also the work s/he is interpreting. This model of agency is better expressed in the French language, where an interprète of Racine's Phèdre can refer polysemically to the scholar who provides a new interpretation of the text and to the actress who plays the protagonist's role. Both are readers and both engage in a hermeneutic experience. But both can also be seen as hackers, insofar as both (discreetly or ostentatiously) over-code the generation of meanings potentially provided by the text: both somewhat "alter" the social existence of Phèdre, either by influencing further readings or by giving the protagonist brown eyes, short hair, a singular tone of voice, etc.

What concerns us here most directly in this collective work-in-progress, however, is that every reader is a potential hacker-if only s/he is taught to read according to the higher potentials of digital literacy, which include most prominently variability, hybridization and remix. And here we can measure quite precisely the shortcomings of the CCSSI and other comparable regulatory documents: they want to program our children to be (well-subjected) readers, not (potentially subversive) hackers. There are good reasons for these principles. But there are equally good reasons to challenge them, namely a need to enable the Bildung of what have now become our computational subjectivities.

Reading texts, updating meanings and hacking the codes can be seen as the three main layers and components of the "computational subjectivity" called for by our digital age. David M. Berry suggests that the brief history of the digital humanities can be mapped in three successive strata-which happen to correspond fairly neatly with these three activities. The first wave merely attempted scientifically to digitalize pre-existing corpuses in order to apply on texts the quantitative super-powers of "machine-reading" (Hayles) - providing merely an augmented way of reading texts. "Digital humanities 2.0 " mobilized the metamedium of the computer playfully to generate new types of multimedial objects never encountered before-allowing interpreters and artists to update meanings by finding creative ways to rearrange and reinvent data. With the "computational turn" brought about by the emergence of software studies (Fuller) and of "cultural software" (Manovich 2013), Berry foresees a third wave of digital humanities for which the central issue will be the exploration of the "computational subjectivity" which may define future generations. This computational subjectivity, one could argue, should constitute the main focus for those who devise standards for today and tomorrow's educational institutions:

the computational subject would know where to recall culture as and when it was needed in conjunction with computationally available others, a just-in-time cultural subject, perhaps, to feed into a certain form of connected computationally supported thinking through and visualised presentation. [...] Bildung is still a key idea in the digital university, not as a subject trained in a vocational fashion to perform instrumental labour, nor as a subject skilled in a national literacy culture, but rather as a subject which can unify the information that society is now producing at increasing rates, and which understands new methods and practices of critical reading (code, data visualisation, patterns, narrative) and is open to new methods of pedagogy to facilitate it. (Berry 2012 14-15)

Italian critic Arturo Mazzarella has convincingly argued that the main features of this apparently radically new computational subjectivity-with its reliance on protocols, data processing, remix, networks and virtual reality - has indeed been explored and enacted by literary experimentations for more than a century. It may be shrewd for literary scholars and teachers to 
reclaim this heritage, in order to show that their field is in the best position to develop the new Bildung of reading, interpretive and hacking skills called for in the digital age.

Literary experience, however, should not be reduced merely to a form of mental gymnastics. Apart from nurturing certain skills, literature also consists in an ethos-i.e., in the respect of a certain form of relation to signs, and to the fellow-humans with whom we share these signs. It is in light of this ethos that the discursive genre exemplified by the CCSSI comes short. Let us raise, as a conclusion, two causes for concern and distrust towards the administrative formulation of common core standards supposed to account for the teaching of reading skills.

1. The transmission of reading, interpretive and hacking skills is more akin to weaving a basket than to programming a computer. In a series of studies devoted to the traditional skills of weaving baskets and of tying string bags, British anthropologist Tim Ingold described how it takes a village to teach young girls how to tie knots with dexterity and efficiency. "It cannot be through the transmission of formulae that skills are passed from generation to generation" (Ingold 2011 353): computers may be programmed through commands defined by their informational content, but humans build skills by imitating gestures and through what Ingold calls "an education of attention" (Ingold 1997; Citton 2013). Critics of the CCSSI are right to denounce the artificial extraction of certain skills from their socio-environmental context-with the appalling consequence of ignoring the obvious "relation between class size and students' success as readers and writers", or of hoping that guidelines and standardized testing will do the job of improving education, while PISA studies show that "mitigating inequities of 'social background' and allocating extra resources to 'socio-economically disadvantaged' schools" may be much better ways to promote reading skills (Ferguson).

But the problem goes much deeper. It is to be located in the very "form" of the guidelines: the inherently bureaucratic "formulae" of the guidelines constitute an obstacle to the effective teaching of skills - especially since, as we all know, they are administratively linked to the nefarious machinery of standardized testing (Davidson 105-131). One should not forget that CCSS guidelines are not directed to students, but to teachers (and to their evaluators): their main issue is not so much learning to read as teaching to read. Teachers should be allowed and encouraged to weave the basket of reading and interpretation through fluid, dexterous and passionate gestures that pupils could imitate and progressively internalize, moved by a contagious love for inspiring cultural works (Steiner). Instead, the formulaic apparatus of administrative standards and guidelines promotes a miseducation of attention, focusing all eyes on abstract standards and test results, rather than on the intuitive attunement of gestures to concrete environments.

2. Learning to read in the digital age means learning to operate simultaneously with and against apparatuses. The true challenge of hacking (as of literary criticism) consists in reaching a very difficult and fragile balance between a necessary respect for the code, without which the exploit will simply not work, and an inherently subversive drive, without which the necessary transgression advocated by Vilém Flusser and Pierre-Damien Huygue will not occur (necessary because our becoming-human depends on it). "Learning" can in no way be equated with conforming to pre-defined rules of engagement. It must include an attitude of playing beyond the limits set by pre-existing rules; it requires the somewhat defiant posture characteristic of the "hacker ethic" (Himanen). A most important skill pedagogues should promote, among teachers and students alike, would be to cultivate a deep and creative distrust against the bureaucratic apparatus of standards and guidelines (not to mention standardized testing).

Our populations have been thinking with paintings and books for several centuries, with moving pictures for a hundred years, and now with computers for a few decades. As algorithms 
geared towards profiling and data mining increasingly compute our minds from the inside, the new Bildung must generate computational subjectivities capable of counter-reading and countereffecting the way we are read and affected by our new machines.

\section{Work Cited}

Barthes, Roland. Criticism and Truth. Minneapolis: University of Minnesota Press, 1987. Print.

Berry, David M. The Philosophy of Software: Code and Mediation in the Digital Age. London: Palgrave Macmillan, 2011. Print.

Berry, David M. Understanding Digital Humanities. London: Palgrave-Macmillan, 2012. Print.

Citton, Yves. Lire, interpréter, actualiser. Pourquoi les études littéraires?, Paris : Éditions Amsterdam, 2007. Print.

Citton, Yves. L'avenir des humanités. Économie de la connaissance ou cultures de l'interprétation ? Paris : Éditions de La Découverte, 2010. Print.

Citton, Yves. "Reading Literature and the Political Ecology of Gestures in the Age of Semiocapitalism”, New Literary History, vol. 44:2, Spring 2013. 285-308. Print.

Citton, Yves. "From Theory to Bricolage: Indiscipline and the Exemplary Gesture of Interpretation". International Social Science Journal $\mathrm{n}^{\circ}$ 207-208, Hoboken, NJ: Wiley and Sons/UNESCO, 2014. 53-66. Print.

Common Core State Standards Initiative. Common Core State Standards Initiative, 2012. What Parents Should Know. http://www.corestandards.org/what-parents-should-know/. Web. 21 August 2014.

Common Core State Standard for English Language Arts \& Literacy in History/Social Studies, Science, and Technical Subjects, 2012, http://www.corestandards.org/wpcontent/uploads/ELA_Standards.pdf. Web. 21 August 2014.

Davidson, Cathy N. Now You See It. How Technology and Brain Science Will Transform Schools and Business for the $21^{\text {st }}$ Century. New York: Penguin, 2011. Print.

Felski, Rita. Uses of Literature. Hoboken, NJ: Wiley-Blackwell, 2008. Print.

Ferguson, Margaret W. "The MLA and the Common Core State Standards Initiative: Continuing the Conversation". MLA Commons. From the President, April 2014. http://president.commons.mla.org/2014/04/16/the-mla-and-the-common-core-state-standardsinitiative-continuing-the-conversation/. Web. 21 August 2014.

Fuller, Matthew. Software Studies. A Lexicon. Cambridge MA: MIT Press, 2008. Print. 
Galloway, Alexander. Protocol. How Control Exists After Decentralization. Cambridge, MA: MIT Press, 2004. Print.

Galloway, Alexander and Thacker, Eugene. The Exploit. A Theory of Networks. Minneapolis: University of Minnesota Press, 2007. Print.

Hayles, Katherine N. How We Think: Digital Media and Contemporary Technogenesis, Chicago: University of Chicago Press, 2012. Print.

Himanen, Pekka. Hacker Ethic and the Spirit of the Information Age. Edinburgh: Floris Books, 1999. Print.

Ingold, Tim. The Perception of the Environment. Essays on Livelihood, Dwelling and Skill, London: Routledge, 2011. Print.

Ingold, Tim. "From the transmission of representation to the education of attention". The Debated Mind: Evolutionary Psychology versus Ethnography. Ed. Harvey Whitehouse (2001). New York: Berg, 2001. 113-153. Available online at http://lchc.ucsd.edu/mca/Paper/ingold/ingold1.htm. Web. 24 October 2013.

Lévi-Strauss, Claude. The Savage Mind. Chicago, IL: Chicago University Press, 1966. Print.

Lessig, Lawrence. Remix. Making Art and Commerce Thrive in the Hybrid Economy. New York: Penguin, 2008.

Manovich, Lev. The Language of New Media. Cambridge, MA: MIT Press, 2001. Print.

Manovich, Lev. Software Takes Command. New York: Bloomsbury, 2013. Print

Mazzarella, Arturo. La grande rete della scrittura. La letteratura dopo la rivoluzione digitale. Torino: Bollati Boringhier, 2008. Print.

McKenzie Wark, Ken. A Hacker Manifesto. Cambridge, MA: Harvard UP, 2004.

Multitudes. Special Issue "Luttes de classes sur le web”. Paris: Inculte, Winter 2014.

Pasquinelli, Matteo. Animal Spirit. A Bestiary of the Commons, Rotterdam, NAI, 2008. Print.

Scholz, Trebor (ed.). Digital Labor. The Internet as Playground and Factory. New York: Routledge, 2013. Print.

Steiner, David. “Our Dogmatic Slumbers.” Profession (2007): 141-49. Print.

Terranova, Tiziana. Network Cultures. Politics for the Information Age, New York: Pluto Press, 2004. Print. 
Bio:

Yves CitTon is professor of French Literature of the 18th Century at the Universite de Grenoble-3, member of the UMR LIRE (CNRS 5611) and co-editor of the journal Multitudes. He taught for 12 years in the department of French and Italian of the University of Pittsburgh, PA, and has been invited Professor at New York University, Harvard, Geneva University and Sciences-Po Paris. He recently published Pour une écologie de l'attention (Seuil, 2014), Gestes d'humanités. Anthropologie sauvage de nos expériences esthétiques (Armand Colin, 2012), Renverser l'insoutenable (Seuil, 2012), Zazirocratie (Éditions Amsterdam, 2011), L'Avenir des Humanités. Économie de la connaissance ou cultures de l'interprétation? (La Découverte, 2010), Mythocratie. Storytelling et imaginaire de gauche (Éditions Amsterdam, 2010) and Lire, interpréter, actualiser. Pourquoi les études littéraires ? (Éditions Amsterdam, 2007). 